\title{
FALAR EM PÚBLICO: RELAÇÕES COM COMPETÊNCIA EM COMUNICAÇÃO, ANSIEDADE E EXPERIÊNCIAS DE
} ORATÓRIA DE DISCENTES

\author{
PUBLIC SPEAKING: RELATIONSHIP WITH COMPETENCY IN COMMUNICATION, ANXIETY AND STUDENT \\ ORATORY EXPERIENCES
}

\section{HABLAR EN PÚBLICO: RELACIÓN CON LA COMPETENCIA EN COMUNICACIÓN, ANSIEDAD Y EXPERIENCIAS ORATORIAS DE ESTUDIANTES}

\author{
Adriana Pereira da Silva Griloํ, Alfredo Almeida Pina-Oliveira², Ana Cláudia Giesbrecht Puggina ${ }^{3}$
}

\begin{abstract}
RESUMO
Objetivos: Correlacionar a competência em comunicação interpessoal e o traço de ansiedade dos discentes de graduação com a autoavaliação ao falar em público; associar as experiências acadêmicas de oratória e sentimentos percebidos nessas situações com a autoavaliação ao falar em público. Método: Estudo transversal quantitativo, realizado em março de 2016 a março de 2017, com discentes do curso de graduação em Enfermagem de duas Instituições de Ensino Superior privadas paulistas. Foram utilizados quatro instrumentos: instrumento de caracterização do participante da pesquisa, a subescala traço de Inventário de Ansiedade, Escala de Competência em Comunicação Interpessoal e a Escala para Autoavaliação ao Falar em Público. Resultados: A amostra do estudo foi constituída de 613 discentes com média de idade de 25,53 ( $\pm 7,93$ ). A maioria nunca participou de curso de teatro ou oratória ( $n=502 ; 81,89 \%$ ), optou por apresentar os trabalhos acadêmicos ( $n=389 ; 63,46 \%)$, considera importante preparar-se com antecedência ( $n=347 ; 56,61 \%)$, preocupa-se em conhecer o perfil do público ( $n=376 ; 61,34 \%)$. A maioria declara que conseguiria manter a calma, em caso de branco ou bloqueio ( $n=585 ; 95,43 \%$ ); já sentiu algum embaraço durante uma apresentação ( $n=454$; 74,06\%). O sentimento predominante, em apresentações públicas, foi a ansiedade ( $n=288 ; 46,98 \%)$. Quanto maior a idade e a competência, em comunicação interpessoal, melhor se autoavalia; quanto maior a ansiedade, pior se autoavalia. Conclusões: Há correlações positivas significativas da idade e da competência em comunicação interpessoal com a autoavaliação positiva do falar em público. Encontrou-se correlação negativa do traço de ansiedade com a autoavaliação positiva ao se expor publicamente.
\end{abstract}

Descritores: Fala; Comunicação; Ansiedade; Relações Interpessoais; Estudantes; Enfermagem.

\section{ABSTRACT}

Objectives: To correlate the competence in interpersonal communication and the anxiety trait of undergraduate students with self-assessment in public speaking; to associate the academic experiences of oratory and feelings perceived in these situations with the self-assessment when speaking in public. Method: Quantitative cross-sectional study conducted from March 2016 to March 2017 with undergraduate nursing students from two private higher education institutions. Four instruments were used: the research participants characterization instrument, the trait subscale of Anxiety Inventory, the Interpersonal Communication Competence Scale and the Public Speaking Self-Assessment Scale. Results: The study sample consisted of 613 students with a mean age of $25.53( \pm 7.93)$. Most students: never participated in theater or oratory course ( $\mathrm{n}=502 ; 81.89 \%)$; chose to present the academic works ( $n=389 ; 63.46 \%)$, considers it important to prepare in advance $(n=347 ; 56.61 \%)$; and are concerned with knowing the profile of the public ( $n=376 ; 61.34 \%$ ). Most students: reported that they would be able to remain calm in the event of a blank or blocked ( $n=$ $585 ; 95.43 \%)$ and have felt a blockage during a presentation $(n=454 ; 74.06 \%)$. The predominant feeling in public presentations was anxiety ( $n=$ 288; 46.98\%). The older the person and the competence in interpersonal communication, the better they evaluate themselves; the higher the anxiety, the worse they evaluate themselves. Conclusions: There are significant positive correlations of age and competence in interpersonal communication with the positive self-assessment of public speaking. A negative correlation of anxiety trait with positive self-assessment was found when exposed publicly.

Keywords: Speech; Communication; Anxiety; Interpersonal Relations; Nursing Students.

\section{RESUMEN}

Objetivos: Correlacionar la competencia en comunicación interpersonal y el rasgo de ansiedad de los estudiantes de pregrado con autoevaluación en hablar en público; asociar las experiencias académicas de oratoria y los sentimientos percibidos en estas situaciones con la autoevaluación cuando se habla en público. Método: Estudio transversal cuantitativo realizado con estudiantes universitarios de enfermería de dos instituciones privadas de educación superior, la recolección de datos se realizó entre marzo de 2016 y marzo de $2017 . S e$ utilizaron cuatro instrumentos: el instrumento de caracterización de participantes en la investigación, la subescala de rasgo del Inventario de Ansiedad, la Escala de Competencia de Comunicación Interpersonal y la Escala de Autoevaluación de Oratoria. Resultados: La muestra del estudio consistió en 613 estudiantes con una edad media de 25.53 ( \pm 7.93 ). La mayoría nunca participó en un curso de teatro u oratoria $(n=502 ; 81.89 \%)$, eligió presentar los trabajos académicos ( $n=389 ; 63.46 \%)$, considera importante prepararse con anticipación ( $n=347 ; 56,61 \%$ ) o se preocupa por conocer el perfil del público ( $n=376 ; 61,34 \%$ ). La mayoría informó que podrían mantener la calma en caso de un espacio en blanco o de bloqueo ( $n=585 ; 95.43 \%$ ); Alguna vez ha sentido un bloqueo durante una presentación $(n=454 ; 74.06 \%)$. El sentimiento predominante en las presentaciones públicas fue ansiedad ( $n=$ $288 ; 46.98 \%$ ). Cuanto mayor es la persona y la competencia en comunicación interpersonal, mejor se evalúan a sí mismos; cuanto mayor es la ansiedad, peor se evalúan a sí mismos. Conclusiones: Existen correlaciones positivas significativas de edad y competencia en la comunicación interpersonal con la autoevaluación positiva de hablar en público. Se encontró una correlación negativa del rasgo de ansiedad con una autoevaluación positiva cuando se expuso públicamente.

Descriptores: Habla; Comunicación; Ansiedad; Relaciones Interpersonales; Estudiantes; Enfermería.

${ }^{1}$ Enfermeira. Aluna de Doutorado do Programa de Pós-Graduação Stricto Sensu em Enfermagem da Universidade Universus Veritas, Guarulhos, SP. ${ }^{2}$ Enfermeiro. Doutor em Ciências pela Escola de Enfermagem da Universidade de São Paulo. Professor Doutor da Universidade Universus Veritas. Guarulhos, SP ${ }^{3}$ Enfermeira. Doutora em Enfermagem pela Escola de Enfermagem da Universidade de São Paulo. Professora Adjunta na Faculdade de Medicina de Jundiaí. Jundiaí, SP. 


\section{INTRODUÇÃO}

Falar em público é apresentar uma mensagem, compartilhá-la e influenciar outras pessoas, sendo essencial para a promoção da interação humana e do entendimento da plateia sobre informações transmitidas por meio de palavras, atos e gestos. Entretanto, para ser um bom comunicador, fazem-se necessários o preparo e o treino ${ }^{(1)}$.

Falar em público corretamente e sem inibições envolve saber transmitir, comunicar e expressar-se adequadamente, sendo que cada audiência influencia sobremaneira como o orador deve se expressar. Por essa razão, desenvolver a sensibilidade, para entender as intenções dos ouvintes e adaptar o conteúdo da mensagem aos interesses desse público-alvo, exige habilidades e experiências em oratória ${ }^{(2)}$.

A oratória consiste na arte de falar bem em público de forma eloquente. Trata-se de uma importante habilidade em comunicação e compreende um método de discurso estabelecido por um conjunto de regras e técnicas que permitem aperfeiçoar as qualidades pessoais de quem pretende falar publicamente ${ }^{(1)}$. As experiências de oratória, no ambiente universitário, são importantes, pois facilitam o reconhecimento das próprias dificuldades e preparam os discentes, para aprenderem a enfrentá-las de maneira positiva, a fim de aprimorarem suas habilidades comunicativas ${ }^{(3)}$.

Habilidades em comunicação têm sido exigidas e valorizadas, em diferentes áreas da formação universitária e, principalmente, quando a atuação profissional se baseia nas relações interpessoais, como é o caso da Enfermagem ${ }^{(4)}$. Nesse sentido, entende-se que a comunicação seja um instrumento básico do cuidar e é relevante, para a assistência em Enfermagem, e o falar em público configura uma situação que profissionais e discentes ainda receiam ou temem ${ }^{(5)}$.

A oralidade norteia o processo de ensino, aprendizagem e a compreensão da fala, tendo em vista que saber comunicar-se efetivamente é essencial para o sucesso acadêmico e profissional( ${ }^{(6)}$. Destarte, torna-se importante 0 desenvolvimento de habilidades em comunicação que facilitem a expressão da oralidade.

É por meio da expressão verbal e não verbal, pública ou interpessoal, que o ser humano manifesta sua própria individualidade. Revelar-se pode causar medo e ansiedade e pode afetar adversamente o sujeito. A incapacidade de dizer claramente aquilo que se deseja, por nervosismo, medo, insegurança ou timidez, pode interferir no desenvolvimento pessoal e profissional ${ }^{(7-8)}$.

Falar bem em público envolve destreza, criatividade, equilíbrio emocional diante da exposição pública, sendo que o comunicador competente é aquele que consegue expressar autocontrole, em situações profissionais, reuniões, entrevistas e discussões em grupo ${ }^{(1)}$.

O início de uma fala pública é o momento mais difícil da apresentação e que mais exige habilidades de autocontrole e domínio da situação. Nesse momento, a adrenalina é liberada, e o indivíduo procura encontrar o melhor local para se posicionar ou ouvir o som da própria voz ${ }^{(2)}$.

O autocontrole é, muitas vezes, percebido pela voz, uma vez que representa um importante indicador do estado afetivo na comunicação, assim como a expressão facial e gestual, que são responsáveis pela comunicação não verbal das emoções ${ }^{(9)}$. Enfatiza-se que o estado emocional impacta diretamente a comunicação verbal e não verbal do indivíduo, em especial, quando ele se expressa em público ${ }^{(10)}$.

O falar em público é considerado um estressor psicossocial associado à ansiedade, ao medo, à insegurança e à presença de pensamentos negativos que são acionados como forma de autopreservação diante da exposição, neste cenário, percebida como ameaçadora, interferindo diretamente nas apresentações ${ }^{(11)}$.

À guisa de síntese, a vida acadêmica apresenta muitas ocorrências de apresentações em público e, por esse motivo, os objetivos deste estudo foram: correlacionar a competência em comunicação interpessoal e o traço de ansiedade dos discentes com a autoavaliação ao falar em público; e associar as experiências acadêmicas em oratória a sentimentos percebidos nessas situações com a autoavaliação do falar em público.

\section{MÉTODO}

Estudo transversal quantitativo que teve como variável de resposta a autoavaliação, ao falar em público e, como variáveis preditoras, a competência em comunicação interpessoal, as características sociodemográficas, a experiência acadêmica de oratória, os sentimentos percebidos pelos discentes nessas situações e o traço de ansiedade.

O cálculo amostral foi determinado pelo desvio-padrão $( \pm 5,90)$ e média $(37,8)$ obtidos em 
relatório científico anterior ${ }^{(12)}$. Com o software Statistical Package for the Social Sciences (SSPS), foi calculado o coeficiente de variação ( $C V=D P / M e ́ d i a ; ~ C V=0,156)$. O erro máximo da estimativa foi estimado pela multiplicação do CV e do DV $(0,156 \times 5,90)$, sendo igual a 0,92 . O nível de significância foi de $5 \%$, e o tamanho amostral mínimo estimado, para a aplicação desse instrumento, foi 158 participantes.

A amostra do estudo foi constituída por 613 discentes dos cursos de graduação em Enfermagem de duas Instituições de Ensino Superior (IES) privadas, com fins lucrativos, localizadas nos municípios de Guarulhos (SP) IES 1 - e São Paulo (SP) - IES 2; participaram 211 discentes da IES 1 e 402 da IES 2.

Adotaram-se os critérios de elegibilidade dos discentes para participar desta pesquisa: ter idade igual ou superior a 18 anos, estar regularmente matriculado do primeiro ao oitavo semestres do curso de graduação em Enfermagem, ser residente no município de São Paulo e região metropolitana nos quais se inserem as IES 1 e IES 2.

Após obter a anuência formal de seus dirigentes, o recrutamento dos participantes foi iniciado em ambas as IES. Os docentes foram abordados, antes de iniciar as aulas e, após sua autorização, a pesquisadora principal apresentou e esclareceu os objetivos e métodos desta pesquisa. Sendo assim, a coleta de dados ocorreu, no período de março de 2016 a março de 2017, e foram selecionados dois momentos para abordar os participantes: intervalo e término de aulas. Na IES 1, foram abordados estudantes dos períodos matutino e noturno, enquanto, na IES 2, participaram estudantes dos períodos matutino, vespertino e noturno. Ressalta-se que as coletas de dados ocorreram, em sala de aula, de maneira coletiva e não houve recusas.

Foram utilizados quatro instrumentos: um questionário de caracterização do participante, o Inventário de Ansiedade Traço-Estado (IDATE), a Escala de Competência em Comunicação Interpessoal ( $\mathrm{ECCl}$ ) e a Escala para Autoavaliação ao Falar em Público (SSPS). Delineou-se a complementaridade desses instrumentos, a fim de identificar características potencialmente relacionadas a traços de ansiedade dos participantes, verificar traços de ansiedade adquiridos, em suas trajetórias de vida, avaliar quão competentes se sentem para se comunicarem de modo interpessoal e analisar possíveis influências, no traço de ansiedade, decorrentes do falar em público. Destaca-se que o recolhimento desses instrumentos ocorreu no mesmo dia de sua aplicação.

O questionário de caracterização do participante foi composto por 22 variáveis, sendo 11 questões sobre características sociodemográficas, tais como idade, sexo, naturalidade, relacionamento afetivo, cor autorreferida, religião, trabalho atual, área de atuação, renda familiar, semestre de graduação e período, além de 11 questões sobre a experiência acadêmica relacionada ao falar em público.

O IDATE é um instrumento composto por duas subescalas distintas de autorrelatório, para aferir dois conceitos distintos de ansiedade, o estado de ansiedade (A-Estado) e o traço de ansiedade (A-Traço). Utilizou-se, neste estudo, apenas a subescala Traço, que avalia como, na maioria das vezes, o participante se sente. É composta por 20 questões mensuradas com escala Likert de 4 pontos (1- quase nunca; 2 - às vezes; 3 - frequentemente; 4 - quase sempre). A variação do escore total da escala foi de 20 a 80: quanto mais alto o escore do IDATE, maior o grau de ansiedade. Essa subescala constituiu-se de 10 itens definidos como sentimentos desagradáveis de tensão e apreensão, conscientemente percebidos, por aumento na atividade do sistema nervoso autônomo. Esses itens possuem codificação reversa (itens $3,4,6,7,9,12,13,14$, 17 e 18$)^{(13)}$.

A $\mathrm{ECCl}$ é um instrumento autoadministrado, composto por 17 itens e cinco domínios de competência de comunicação interpessoal: autorrevelação, assertividade, manejo das interações, disponibilidade e controle do ambiente. A variação do escore total da escala foi de 17 a 85: quanto mais alto o escore da $\mathrm{ECCl}$, maior a competência em comunicação interpessoal do indivíduo. Em cada afirmativa, o participante circulou a resposta que melhor refletisse sua comunicação com os outros: (5) representa quase sempre, (4) geralmente, (3) às vezes, (2) raramente, (1) nunca. Apresentou dois itens com codificação reversa (oito e 17) e quanto maior a pontuação, maior foi a habilidade em comunicação interpessoal ${ }^{(14)}$.

A SSPS é um instrumento composto por 10 afirmativas mensuradas com escala Likert de 6 pontos (de 0 a 5 pontos), em que apenas as duas pontuações extremas foram mencionadas: zero (0) representa discordar totalmente e cinco (5) concordar inteiramente com a afirmação. Os 
itens 1, 3, 5, 6, 9 (Fator 2) representam uma autoavaliação positiva. Os itens 2, 4, 7, 8, 10 (Fator 1) representam uma autoavaliação negativa e foram recodificados para a obtenção do escore final do instrumento. O escore total máximo foi de 50 pontos, sendo esse o somatório da pontuação dos itens das subescalas positiva e negativa. É importante salientar que a pontuação dos itens da subescala negativa foi invertida. A consistência interna apresentou um alfa de Cronbach de 0,90, para a escala total, 0,80 para a subescala de autoavaliação positiva e 0,78 para a subescala de autoavaliação negativa; quanto maior a pontuação, maior a autoavaliação negativa ${ }^{(11)}$.

Os dados foram analisados pelo programa estatístico R Core Team $201{ }^{\circledR}$ (GPL, 2016, Viena: Áustria). Foi realizada análise descritiva e inferencial. Para a comparação das variáveis quantitativas com os escores do instrumento, foi utilizado o Teste de Correlação de Spearman; na associação das variáveis categóricas com os escores, foram utilizados o Teste de Kruskal-Wallis e o Teste Wilconxon de Mann-Whitney. $O$ nível de significância adotado nos testes foi de 0,05. Quando o teste de associação foi significativo, foram analisados os p-valores nas comparações dois a dois pelo critério de Bonferroni; os grupos diferentes entre si foram aqueles com $p$-valores menores que $o$ geral. Os dados faltantes, nos instrumentos psicométricos, foram imputados usando a moda.

O desenvolvimento do estudo seguiu as recomendações da Resolução $n^{\circ}$ 466/2012 e foi aprovado pelo Comitê de Ética e Pesquisa da IES proponente sob Parecer $\mathrm{N}^{\circ} \quad 1.349 .877 \mathrm{e}$ Certificado de Apresentação para Apreciação Ética (CAEE) N 50610315.7.0000.5506. Reitera-se que todos os participantes assinaram o Termo de Consentimento Livre e Esclarecido (TCLE).

\section{RESULTADOS}

A amostra do estudo foi constituída por 613 discentes com média de idade de 25,53 $( \pm 7,93)$. Na IES 1 , foram coletados os questionários de 211 (34,42\%) discentes e, na IES 2, 402 (65,58\%). A maioria era do sexo feminino ( $n=490 ; 79,93 \%)$, natural de São Paulo $(n=450$; $73,41 \%)$, que trabalha $(n=415 ; 67,70 \%)$, sem companheiro fixo ( $n=364 ; 59,38 \%)$, branca ( $n=319 ; 52,04 \%)$ e que estuda no período matutino ( $n=340 ; 55,46 \%$ ).

Maior frequência de católicos $(n=256$; $41,76 \%)$, com renda de até três salários mínimos $(n=140 ; 22,84 \%)$, trabalha na área de enfermagem ( $n=206 ; 33,61 \%)$, está cursando o segundo semestre de graduação ( $n=225 ; 36,70 \%)$ e terceiro semestre de graduação $(n=139$; $22,68 \%$ ) em período noturno ( $n=246,40,13 \%)$.

Considerando as experiências acadêmicas, a maioria nunca participou de curso de teatro ou oratória ( $n=502 ; 81,89 \%)$, optou por apresentar os trabalhos acadêmicos ( $n=389 ; 63,46 \%)$, considera importante preparar-se com antecedência ( $n=347 ; 56,61 \%)$, preocupa-se em conhecer o perfil do público, para se sentir mais seguro ( $n=376 ; 61,34 \%)$ e não se considera criativo, durante o falar em público $(n=349$; $56,93 \%$ ). Encontraram-se maiores frequências de discentes que se consideram pouco tímidos ( $n=303 ; 49,43 \%$ ) e ensaiam a apresentação para outras pessoas ( $n=269 ; 43,88 \%$ ).

Em relação aos sentimentos e sinais não verbais, a maioria destacou que conseguiria manter a calma, em caso de branco ou bloqueio ( $n=585 ; 95,43 \%)$ e já sentiu algum bloqueio, durante uma apresentação, quase não conseguindo falar $(n=454 ; 74,06 \%)$. Destaca-se que o sentimento predominante, em apresentações em público, foi ansiedade $(n=288$; $46,98 \%$ ), sendo o seu principal sinal tremores nas mãos ( $n=201 ; 32,79 \%$ ).

Considerando o ponto médio e o escore médio total dos instrumentos utilizados neste estudo, os discentes, em geral, apresentaram de moderada a alta competência, em comunicação interpessoal, baixo a moderado traço de ansiedade e moderada habilidade em falar em público (Tabela 1).

Tabela 1 - Descrição do escore total dos instrumentos utilizados neste estudo: SSPS, IDATE-Traço e ECCI. São Paulo, 2018.

\begin{tabular}{lcccccccc} 
& $\begin{array}{c}\mathbf{N}^{\circ} \text { de } \\
\text { itens }\end{array}$ & $\begin{array}{c}\text { Variação do } \\
\text { escore }\end{array}$ & $\begin{array}{c}\text { Ponto } \\
\text { Médio }\end{array}$ & Média & $\begin{array}{c}\text { Desvio- } \\
\text { padrão }\end{array}$ & Mínimo & Mediana & Máximo \\
\hline ECCl & 17 & $17-85$ & 51 & 61,84 & 8,10 & 36 & 62 \\
IDATE - Traço & 20 & $20-80$ & 50 & 42,21 & 9,08 & 21 & 41 & 70 \\
SSPS & 10 & $0-50$ & 30 & 34,62 & 5,78 & 35 & 47 \\
\hline \hline
\end{tabular}

Fonte: Elaborada pelos próprios autores.Os itens com codificação reversa já estão recodificados nesta tabela. 
A análise descritiva das respostas dos discentes, baseada nesses três instrumentos, revelou que eles procuram olhar os colegas nos olhos, durante uma conversa, permitem que os amigos os conheçam melhor, defendem seus direitos, são felizes, sentem-se bem, consideram- se pessoas estáveis; em relação ao falar em público, encaram um provável fracasso com tranquilidade, pois acreditam que, mesmo que não acertem por ser uma situação difícil, seja preciso tentar (Tabela 2).

Tabela 2 -- Descrição das respostas dos discentes nos instrumentos utilizados neste estudo: SSPS, IDATETraço e ECCI. São Paulo, 2018.

\begin{tabular}{|c|c|c|c|}
\hline & Instrumentos & Média & DP \\
\hline \multicolumn{4}{|c|}{$\mathrm{ECCl}$} \\
\hline 14 & Tento olhar os outros nos olhos quando falo com eles. & 4,26 & 0,96 \\
\hline 11 & Permito que os amigos vejam quem realmente sou. & 4,19 & 1,04 \\
\hline 1 & Defendo meus direitos. & 4,17 & 0,88 \\
\hline 10 & Meus amigos realmente acreditam que me preocupo com eles. & 4,08 & 0,94 \\
\hline 9 & Deixo que os outros saibam que compreendo o que eles dizem. & 3,87 & 0,94 \\
\hline 2 & Em conversas com amigos, percebo não apenas o que eles dizem, mas o que não dizem. & 3,81 & 1,02 \\
\hline 16 & Outras pessoas acham que eu as entendo. & 3,71 & 0,97 \\
\hline 12 & Outros me descreveriam como caloroso, ou seja, afetuoso. & 3,7 & 1,16 \\
\hline 13 & Expresso-me bem verbalmente. & 3,64 & 1,08 \\
\hline 15 & Quando sou injustiçado, confronto a pessoa que me injustiçou. & 3,56 & 1,26 \\
\hline 7 & Atinjo meus objetivos de comunicação. & 3,52 & 1,01 \\
\hline 6 & Digo às pessoas quando me sinto próxima delas. & 3,37 & 1,22 \\
\hline 3 & Consigo persuadir os outros quanto à minha opinião. & 3,23 & 0,92 \\
\hline 5 & $\begin{array}{l}\text { Assumo o controle das conversas em que estou envolvido, negociando os tópicos sobre os } \\
\text { quais falaremos. }\end{array}$ & 3,23 & 1,11 \\
\hline 17 & É difícil encontrar as palavras certas para me expressar. & 3,00 & 1,22 \\
\hline 4 & Revelo como me sinto para os outros. & 2,89 & 1,24 \\
\hline 8 & Tenho dificuldade em me defender. & 2,39 & 1,15 \\
\hline \multicolumn{4}{|c|}{ IDATE - TRAÇO } \\
\hline 10 & Sou feliz. & 3,28 & 0,77 \\
\hline 1 & Sinto bem. & 3,02 & 0,89 \\
\hline 19 & Sou uma pessoa estável. & 2,84 & 0,87 \\
\hline 16 & Estou satisfeito. & 2,77 & 0,89 \\
\hline 13 & Sinto-me seguro. & 2,72 & 0,93 \\
\hline 20 & Fico tenso e preocupado quando penso em meus problemas do momento. & 2,68 & 0,99 \\
\hline 7 & Sou calmo, ponderado e senhor de mim mesmo. & 2,55 & 0,96 \\
\hline 14 & Evito ter que enfrentar crises ou problemas. & 2,37 & 1,05 \\
\hline 11 & Deixo-me afetar muito pelas coisas. & 2,31 & 0,97 \\
\hline 9 & Preocupo-me demais com as coisas sem importância. & 2,22 & 1,02 \\
\hline 6 & Sinto-me descansado. & 2,12 & 0,89 \\
\hline 18 & Levo os desapontamentos tão a sério que não consigo tirá-los da cabeça. & 2,11 & 1,05 \\
\hline 2 & Canso-me facilmente. & 2,09 & 0,82 \\
\hline 17 & Ideias sem importância me entram na cabeça e ficam me preocupando. & 2,04 & 0,99 \\
\hline 8 & Sinto que as dificuldades estão se acumulando de tal forma que não consigo resolver. & 1,91 & 0,86 \\
\hline 12 & Não tenho muita confiança em mim mesmo. & 1,85 & 0,93 \\
\hline 4 & Gostaria de poder ser tão feliz quanto os outros parecem ser. & 1,83 & 0,97 \\
\hline 5 & Perco oportunidades porque não consigo tomar decisões rapidamente. & 1,78 & 0,86 \\
\hline 3 & Tenho vontade de chorar. & 1,71 & 0,83 \\
\hline 15 & Sinto-me deprimido. & 1,60 & 0,82 \\
\hline
\end{tabular}

"continua na página seguinte" 


\begin{tabular}{|c|c|c|c|}
\hline \multicolumn{2}{|r|}{ Instrumentos } & \multirow[t]{2}{*}{ Média } & \multirow[t]{2}{*}{ DP } \\
\hline \multicolumn{2}{|r|}{ SSPS } & & \\
\hline 5 & Mesmo que não dê certo, não é o fim do mundo. & 4,12 & 1,39 \\
\hline 3 & Esta é uma situação difícil, mas posso dar conta dela. & 3,91 & 1,26 \\
\hline 1 & O que tenho a perder vale a pena tentar. & 3,68 & 1,53 \\
\hline 9 & Em vez de me preocupar, poderia me concentrar no que quero dizer. & 3,52 & 1,46 \\
\hline 6 & Posso dar conta de tudo. & 2,92 & 1,46 \\
\hline 7 & Qualquer coisa que eu disser vai parecer bobagem. & 1,49 & 1,49 \\
\hline 10 & Eu me sinto desajeitado e tolo, certamente eles irão notar. & 1,38 & 1,67 \\
\hline 4 & Um fracasso nesta situação seria mais uma prova da minha incompetência. & 1,14 & 1,61 \\
\hline 8 & Acho que vou me dar mal de qualquer jeito. & 1,03 & 1,46 \\
\hline 2 & Sou um fracassado. & 0,55 & 1,23 \\
\hline
\end{tabular}

Fonte: Elaborada pelos próprios autores.

Com o aumento da idade, as notas da subescala positiva da SSPS tendem a aumentar. Quando o traço de ansiedade aumenta, a subescala negativa da autoavaliação, ao falar em público, tende a ser maior, e a subescala positiva tende a ser menor. Quanto maior a competência em comunicação interpessoal, melhor é a autoavaliação ao falar em público (Figura 1).

Figura 1 - Correlações estatisticamente significantes entre idade, ECCI e IDADE-Traço com a escala SSPS.
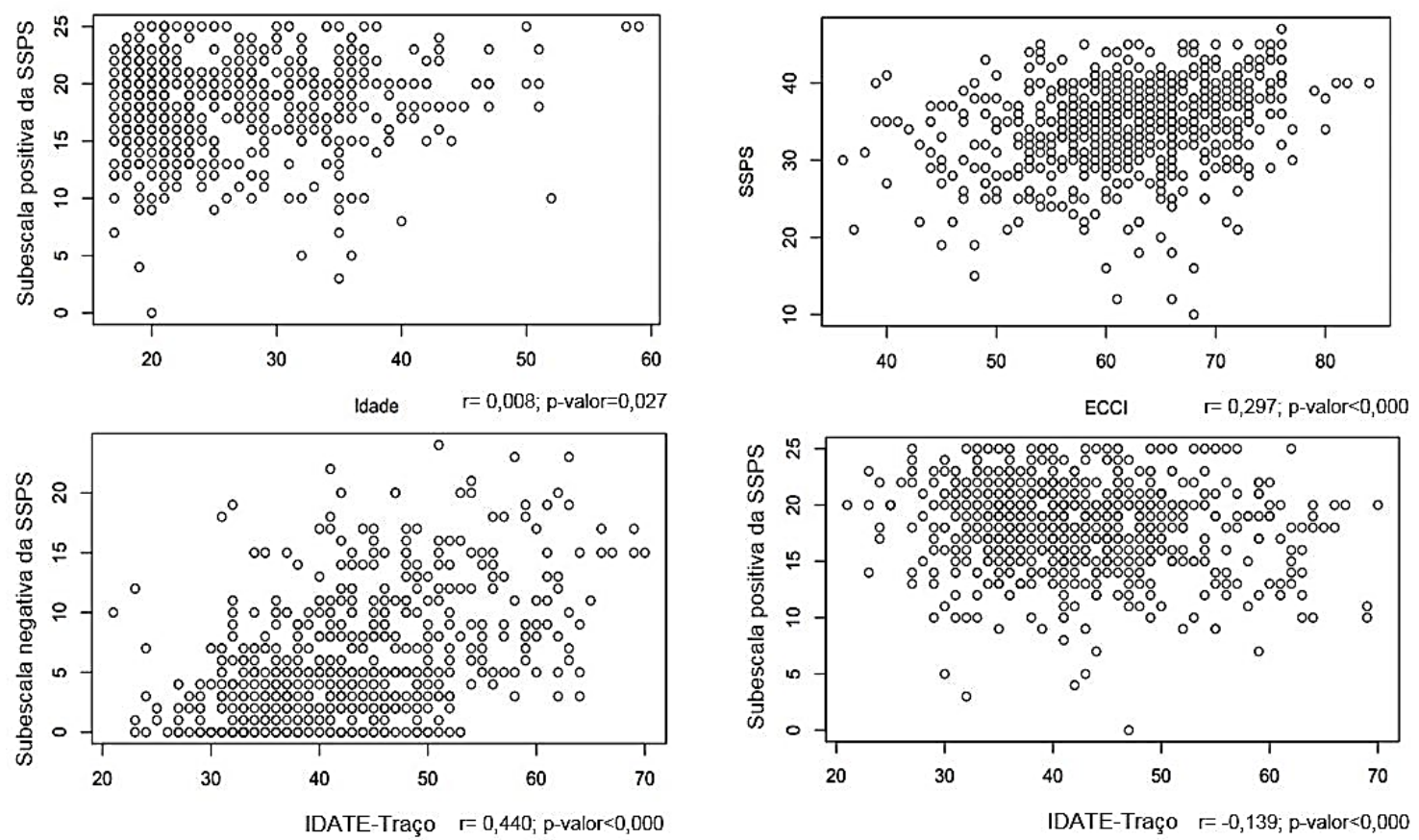

SSPS: Escala para Autoavaliação ao Falar em Público. ECCI: Escala de Competência em Comunicação Interpessoal. IDATE-Traço: Inventário Traço e Estado de Ansiedade - subescala Traço. r: razão de Correlação de Spearman. p-valor: nível de significância. Teste de Correlação de Spearman.

Aqueles discentes que não apresentaram trabalhos obrigatórios com apresentação pública, que já se bloquearam ao falar em público, que não se sentem criativos, durante uma oratória e entrariam em desespero e abandonariam a apresentação, em caso de branco ou bloqueio, durante uma apresentação, tendem a ter nota maior da subescala negativa da SSPS (Figura 2). 
Figura 2 - Associações estatisticamente significantes entre variáveis com duas categorias com a escala SSPS.
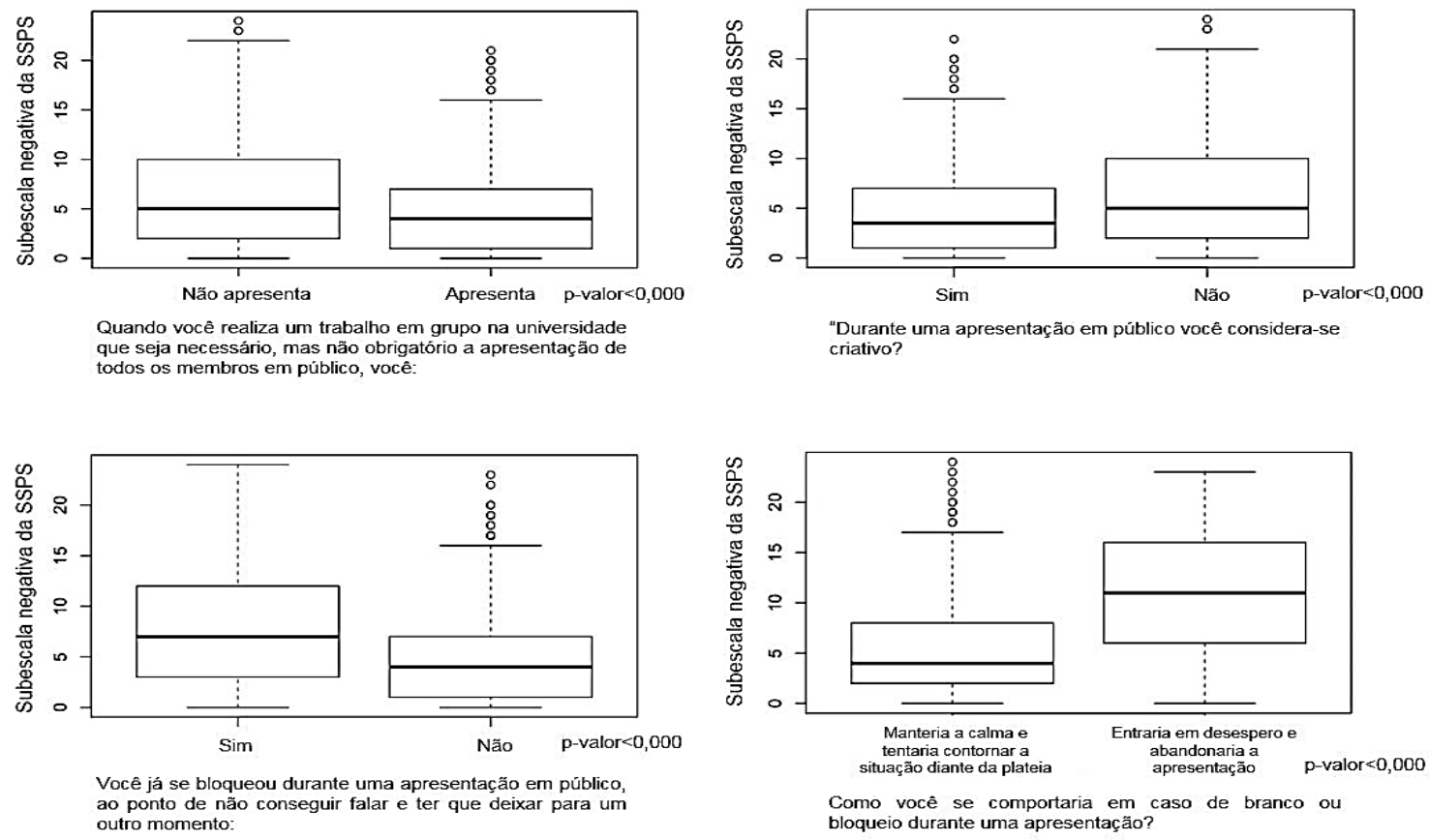

Teste de Kruskal-Wallis.

Você já se bloqueou durante uma apresentação em público ao ponto de não conseguir falar e ter que deixar para um

Quanto mais a pessoa se considera tímida, maior tende a ser sua nota da subescala negativa. Apenas não houve diferença significativa entre aqueles pouco e muito pouco tímidos e entre aqueles muito e pouco tímidos. Aqueles que sentem medo tendem a ter notas maiores da

subescala negativa que aqueles que sentem ansiedade. Aqueles que se preparam com antecedência tendem a ter notas menores de subescala negativa que aqueles que se preparam de última hora (Figura 3).

Figura 3 - Associações estatisticamente significantes entre variáveis com três ou mais categorias com a escala SSPS.

A

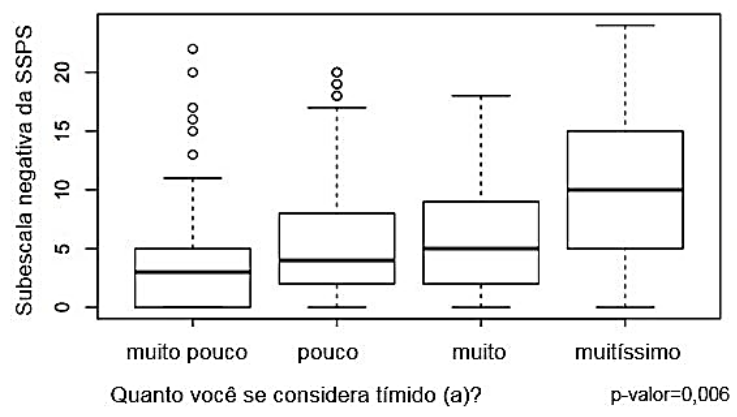

C

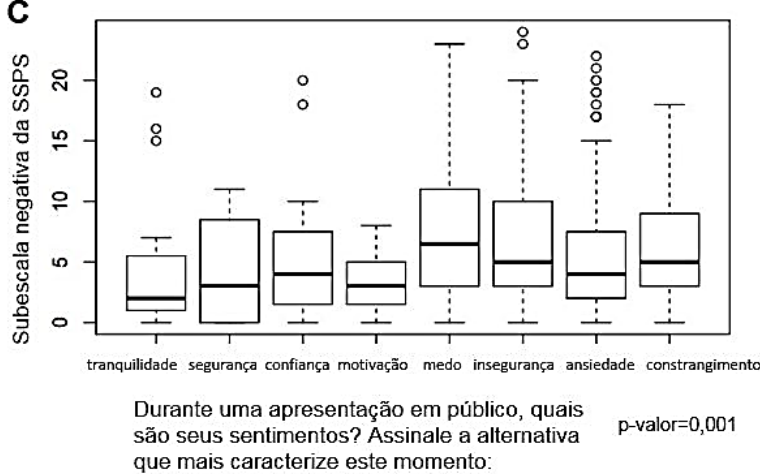

B

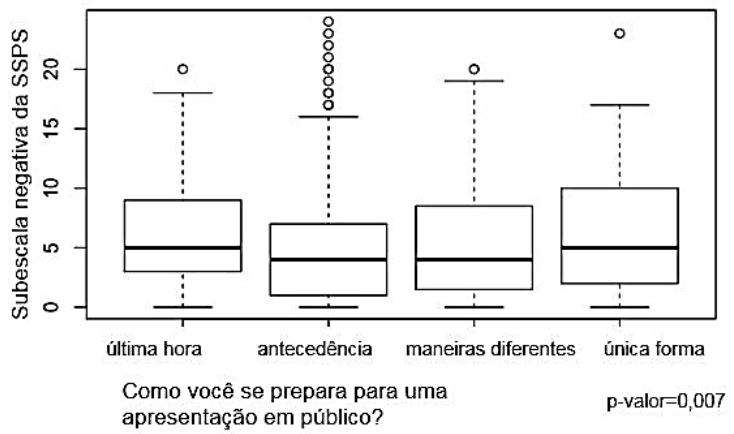

Teste de Kruskal-Wallis. A: Resultado do Teste de Bonferoni: muito pouco versus muito ( $p$-valor $<0,000)$, muito pouco versus muitíssimo ( $p$ valor $<0,000)$, pouco versus muitíssimo ( $p$-valor $<0,000)$, muito versus muitíssimo $(p$-valor $<0,000)$. B: Resultado do Teste de Bonferroni: antecedência versus última hora $(\mathrm{p}=0,006)$. C: Resultado do Teste de Bonferroni: medo versus ansiedade ( $\mathrm{p}$-valor $<0,000)$. 


\section{DISCUSSÃO}

As contribuições do atual estudo referemse às relações positivas da idade com a fala pública, pois quanto mais velha a pessoa, melhor é sua performance e competência em comunicarse publicamente, assim como quanto melhor forem as habilidades interpessoais de um indivíduo, melhor será sua autoavaliação e, consequentemente, mais à vontade a pessoa se sente ao falar publicamente.

Em estudo japonês ${ }^{(15)}$, constatou-se que o medo de falar em público tende a diminuir com a idade, cuja prevalência foi associada a 7,3\% dos estudantes adolescentes japoneses, sendo maior entre as meninas e associado a psicopatologias, tais como: depressão e ansiedade, pensamentos suicidas, autolesão deliberada, violência contra objetos e pessoas e aumento das dificuldades na escola. Esses dados reforçam a necessidade de não minimizar a importância de criar oportunidades para a superação do temor em falar em público.

Em outro estudo sobre a prevalência do medo de falar em público entre universitários, observaram-se $63,9 \%$ dessa condição, na população estudada e $89,3 \%$ dessa parcela gostaria que seu programa de graduação incluísse aulas para melhorar o discurso em público. Também foi observado que esse medo é mais prevalente entre as mulheres, estudantes que participam de poucas atividades que envolvem falar com grupos de pessoas e aqueles que têm uma autopercepção de sua voz nos extremos, muito alta ou baixa ${ }^{(16)}$.

Essa atenção aos sinais paralinguísticos apresenta relações diretas com a habilidade em comunicação e indica a necessidade de treinamentos a fim de conscientização e reduzir a frequência de pausas preenchidas, que ocorrem durante o discurso público ("uh", "um" ou "er"), e o uso indevido de palavras que demostram nervosismo ("tipo assim") podem melhorar a comunicação do indivíduo e, em consequência, seu desempenho ao falar em público ${ }^{(17-18)}$.

Em um estudo do tipo antes e depois, relacionado a dois modelos de cursos sobre falar em público e seus efeitos sobre a autopercepção de confiança, competência e apreensão, associados ao falar em público, foram identificados menor apreensão e aumento dos sentimentos de confiança e competência, em comunicação dos alunos de graduação, após os cursos: um focado no conhecimento do mecanismo vocal e características paralinguísticas e outro abordando a teoria geral da comunicação e falar em público ${ }^{(19)}$.

$O$ atual estudo também reforça a influência negativa da ansiedade, ao falar em público e corrobora com resultados similares na literatura científica ${ }^{(20-21)}$. Pesquisadores examinaram a reatividade do estresse fisiológico multissistema de alto risco, no contexto de falar em público, em estudantes universitários. Amostras de saliva foram testadas, para alfa-amilase, cortisol e interleucina- 1 beta (IL-1 $\beta$ ). Ansiedade de comunicação autorreferida, ansiedade de interação social, sensibilidade à rejeição e sexo foram avaliados como fatores de risco para maior reatividade ao estresse. Os autores encontraram que a alfa-amilase salivar, cortisol e IL-1 $\beta$ mudaram, significativamente, após início da fala. Além disso, níveis elevados de ansiedade de comunicação autorreferida e ansiedade de interação social foram independentemente associados com respostas aumentadas de cortisol e IL-1 $\beta$ e combinadas para aumentar a atividade do eixo HPA e da citocina inflamatória. Os autores concluíram que os indivíduos com medo de interação e de comunicação elevado podem apresentar respostas neuroendócrinas e inflamatórias elevadas, após a exposição a estressores sociais, com consequências de saúde desconhecidas e, provavelmente insalubres, ao longo do tempo ${ }^{(20)}$.

Experiências acadêmicas estressantes podem colaborar, para o aparecimento de transtornos ansiosos e depressivos, prejudicando as relações interpessoais e o bom desempenho dos estudantes na universidade $(4,8,22,24)$. A presença de sintomas autonômicos (taquicardia, rubor facial, tremor e sudorese), comportamentais (esquiva, congelamento e fuga) e cognitivos (avaliação negativa e humilhação), durante as apresentações acadêmicas, são comuns e alarmantes ${ }^{(24)}$.

Realmente, a ansiedade é uma reação natural que incentiva o ser humano a buscar por seus objetivos. No entanto, quando essa reação é muito intensa, ela pode se tornar disfuncional e limitante, dificultando a capacidade de adequação e de enfrentamento diante de situações cotidianas ${ }^{(22)}$.

Ansiedade ao falar em público pode desencadear sentimentos negativos e impactar diretamente a vida pessoal e acadêmica dos discentes. A fala acadêmica, em apresentações 
em público, pode despertar medo e insegurança; complicadores nessas situações estão associados à falta de habilidade em comunicação e à ausência do domínio sobre o assunto, o que predispõe a uma autoavaliação negativa ${ }^{(21,23-24)}$.

Resultados de estudo realizado com enfermeiros estudantes de mestrado mostraram que a ansiedade é a emoção mais presente, nas apresentações em público e que a possibilidade de discussão proporciona mais fatores positivos, perante a fala pública, ajudando-os na superação do medo e no controle da ansiedade ${ }^{(21)}$. Outro estudo realizado com enfermeiros mestrandos, também, identificou a ansiedade como a emoção mais frequente ao falar em público. Além disso, os autores destacaram que o planejamento, o domínio do conteúdo e falar com clareza e objetividade foram características valorizadas pelos participantes ${ }^{(5)}$.

Outras relações encontradas neste estudo contribuem à compreensão do problema e à construção de estratégias para melhorá-lo. São exatamente os alunos que dificilmente se voluntariam, para apresentar trabalhos, que não se sentem criativos, já vivenciaram situações de bloqueio ou branco, sentem-se tímidos e com medo, que precisam de auxílio, durante a graduação, para melhorar suas aptidões em eloquência.

Características do falar em público convergentes com outros estudos foram: comprometimento e responsabilidade, cooperação e trabalho em equipe, capacidade de manter bons relacionamentos interpessoais, habilidades de comunicação, criatividade e autocontrole emocional, sendo que as competências sociais são valorizadas no ambiente acadêmico e elas colaboram para a formação de competências e qualificação desses futuros profissionais ${ }^{(25)}$.

A prática de respiração alternada, durante 15 minutos em jovens adultos saudáveis, que já faziam yoga, apresentou um potencial efeito ansiolítico, em situações de estresse agudo, quando comparado ao grupo controle que permaneceu, em uma sala silenciosa, antes de participar da simulação de fala pública ${ }^{(26)}$.

O preparo, o treino e o (auto)conhecimento são primordiais, para diminuir a ansiedade e o nervosismo, durante o falar em público, nas atividades acadêmicas, manifestados por voz trêmula, respiração ofegante e perda ou diminuição da concentração. A exiguidade de oportunidades, para desenvolver as competências de oratória em discentes, pode implicar a ansiedade ao falar em público e dificuldades em relacionamentos interpessoais em suas futuras inserções profissionais ${ }^{(27)}$.

Entretanto saber administrar insucessos na fala pública é um fator importante, pois os indivíduos precisam lidar com tranquilidade tal situação com o intuito de aprimorar essa habilidade ${ }^{(28)}$. Por outro lado, quando se é jovem, falhas, no processo de falar em público, apresentam menor efeito negativo à imagem do orador aprendiz, mas, na vida profissional, podem tornar-se barreiras ao crescimento profissional, comprometer posições arduamente conquistadas e interromper trajetórias profissionais em ascensão(2).

Diante da necessidade de treinamento sem exposição, pesquisadores têm estudado diferentes estratégias ${ }^{(27,29-30)}$. Exemplifica-se um dos estudos que objetivou reduzir a ansiedade excessiva, em universitários, durante exposições orais, em sala de aula. Para isso, empregaram-se preleção e leitura de textos didáticos, treinamento em relaxamento, exercícios de respiração, reestruturação cognitiva, treinamento em habilidades sociais com ênfase em apresentações em público, sendo constatada uma redução considerável, na ansiedade dos universitários e na melhoria da qualidade de vida acadêmico-social, mesmo que a frequência cardíaca não sofra alteração significativa ${ }^{(27)}$.

Em estudo holandês, foi utilizada audiência gravada, projetada em tamanho real e sem trilha sonora; o público foi filmado, em um ambiente de sala de aula, orientado a entrar na sala, ocupar seus lugares, olhar para a câmera e a se comportar de maneira neutra. Essa estratégia induziu uma resposta moderada de estresse: os participantes sentiram-se nervosos, com aumento da frequência cardíaca, suor nas mãos, bem como um efeito de antecipação e uma resposta substancial de cortisol foram observados em $55 \%$ dos participantes. Apesar da resposta de estresse dos discentes, essa estratégia pode se mostrar positiva por não representar uma audiência real e deixar o participante mais confortável no treino e no fracasso $^{(29)}$.

Outros pesquisadores avaliaram a ansiedade, ao falar em público de estudantes, por meio de uma exposição gradual a gravações em vídeo de $360^{\circ}$ de uma sala de aula, apresentando três situações: sala de aula vazia, com uma pequena e grande audiência. Os níveis de 
ansiedade foram medidos, antes e depois de cada sessão, durante um período de quatro semanas. Evidenciou-se a diminuição significativa da ansiedade, após a conclusão de todas as sessões de treinamento, e o decréscimo foi maior nos participantes com níveis iniciais mais altos de ansiedade ${ }^{(30)}$.

Situações simuladas podem ter um efeito positivo, no aprimoramento da fala pública, mesmo que o discurso público, em situações reais, represente estratégia mais efetiva na indução da ansiedade ${ }^{(31)}$. Dessa forma, estratégias que trabalhem situações reais, nas Instituições de Ensino, são oportunas para o desenvolvimento de habilidades comunicativas dos discentes. Portanto refletir e discutir sobre os fatores favoráveis ou dificultadores desse processo de aprendizagem de habilidades desde a graduação podem tornar a futura comunicação profissional clara, efetiva e competente ${ }^{(32-33)}$.

As limitações desta pesquisa referem-se ao tipo de estudo transversal, por meio do qual são possíveis apenas associações e não estabelecimento de causalidade; ao número amostral coletado, em cada uma das IES, que pelas associações propostas esse número poderia ter sido maior; e a distribuição dos discentes participantes, que não foi homogênea em relação aos semestres do curso de graduação em Enfermagem.

Em suma, o presente estudo proporciona elementos estratégicos, para induzir mudanças institucionais e as estratégias de ensino empregadas pelos docentes de Enfermagem, para minimizar as dificuldades discentes, ao executar atividades acadêmicas relacionadas ao falar em público e sua autoavaliação, em tais experiências de oratória, no ambiente universitário e, por conseguinte, contribuir para a formação do profissional enfermeiro.

\section{CONCLUSÃO}

Há correlações positivas significativas da idade e da competência em comunicação interpessoal com a autoavaliação positiva do falar em público. Encontrou-se uma correlação negativa do traço de ansiedade com uma autoavaliação positiva ao se expor publicamente.

Neste estudo, encontraram-se associações significativas de uma autoavaliação negativa do falar em público com as situações: quando o discente não se voluntaria a apresentar os trabalhos acadêmicos, não se sente criativo, durante uma apresentação, já vivenciou um bloqueio, entraria em desespero, em caso de um branco, considera-se uma pessoa muito tímida, sente medo nessa situação pública e não se prepara com antecedência.

\section{REFERÊNCIAS}

1- Lucas SE. A arte de falar em público. 11a edição. Porto Alegre: AMGH; 2014.

2- Polito R. Como falar corretamente e sem inibições. 111a ed. São Paulo: Saraiva; 2015.

3- Ferreira NG. O aperfeiçoamento da comunicação organizacional através da oratória [monografia]. Brasília: Centro Universitário de Brasília; 2014.

4- Bandeira M, Quaglia MAC. Habilidades sociais de estudantes universitários: Identificação de situações sociais significativas. Interaçao Psicol. 2005;9(1):45-55. DOI: 10.5380/psi.v9i1.3285

5- Faria MFG, Fernandes SG, Pirolo SM, Silva MJP. Public speaking: View from master's students in nursing. Rev Esc Enferm USP 1998;32(1):59-66. DOI: $10.1590 /$ s0080-62341998000100009

6- Ortiz JMS, Guerra NEB. Desarrollo de competencias comunicativas mediante la lectura, crítica, escritura creativa y expresión oral. Journal Encuentros 2015;1(13):117-41. DOI: 10.15665/re.v13i2.502

7- Fonseca JG, Pacini CA. Medo de falar em público em uma amostra da população: Prevalência, impacto no funcionamento pessoal e tratamento. Psic Teor Pesqui. 2005;21(2):237-42. DOI: $10.1590 /$ S0102-37722005000200014

8- Carnegie D. Como falar em público e influenciar pessoas no mundo dos negócios. 8a ed. Rio de Janeiro: Record; 2010.

9- Ekman P. A linguagem das emoções. São Paulo: Leya; 2010.

10- Almeida AAF, Behlau M, Leite JR. Correlação entre ansiedade e performance comunicativa. Rev Soc Bras Fonoaudiol. 2011;16 (4):384-89. DOI: 10.1590/S151680342011000400004

11- Osório FL, Crippa JAS, Loureiro SR. Escala para auto-avaliação ao falar em público (SSPS): Adaptação transcultural e consistência interna da versão brasileira. Rev Psiquiatr Clín. 2008;35(6):207-11. DOI: $\underline{10.1590 / \mathrm{S} 010160832008000600001}$

12- Lima GN, Kajiwara GA, Valadares MA, Grilo APS, Puggina AC. Relação entre a autoavaliação do falar em público e emoções que emergem durante visualização da sua própria performance. Perspect Méd. 2017; 28(3):38-9. DOI: 10.6006 13- Spielberger CD, Natalício L, Biaggio MA. Desenvolvimento da forma experimental em 
português do Inventário de Ansiedade TraçoEstado (IDATE). Arq Bras Psicol Apl. 1997 [citado em 15 jan 2018]; 29(3):31-44. Available in: http://bibliotecadigital.fgv.br/ojs/index.php/abpa /article/view/17827

14- Puggina AC, Silva MJP. Interpersonal communication competence scale: Brazilian translation, validation and cultural adaptation. Acta Paul Enferm. 2014;27(2):108-14. DOI: 10.1590/1982-0194201400020

15- Furukawa TA, Watanabe $N$, Kinoshita $Y$, Kinoshita K, Sasaki T, Nishida A, et al. Public speaking fears and their correlates among 17,615 Japanese adolescents. Asia Pac Psychiatry 2014;6(1):99-104. DOI: $\quad$ 10.1111/i.1758$\underline{5872.2012 .00184}$

16- Marinho AC F, Medeiros AM, Gama ACC, Teixeira LC. Fear of public speaking: Perception of college students and correlates. J Voice 2017;31(1):127.e7-e11.

DOI:

\subsection{6/j.jvoice.2015.12.012}

17- Spieler C, Miltenberger R. Using awareness training to decrease nervous habits during public speaking. J Appl Behav Anal. 2017;50(1):38-47. DOI: 10.1002/iaba.362

18- Mancuso C, Miltenberger RG. Using habit reversal to decrease filled pauses in public speaking. J Appl Behav Anal. 2016;49(1):188-92. DOI: $10.1002 / j a b a .267$

19- Hancock AB, Stone MD, Brundage SB, Zeigler MT. Public speaking attitudes: does curriculum make a difference? J Voice 2010;24(3):302-7. DOI: 10.1016/i.jvoice.2008.09.007

20- Auer BJ, Calvi JL, Jordan NM, Schrader D, Byrd-Craven J. Communication and social interaction anxiety enhance interleukin-1 beta and cortisol reactivity during high-stakes public speaking. Psychoneuroendocrinology 2018;94:8390. DOI: 10.1016/i.psyneuen.2018.05.011

21- Souza RASA. Aspectos da expressividade de universitários em situação de apresentação de seminários: Análise em pré e pós-intervenção fonoaudiológica [dissertação]. São Paulo: Pontifícia Universidade Católica; 2007.

22- Chaves ECL, Lunes DH, Moura CC, Carvalho LC, Silva AM, Carvalho EC. Anxiety and spirituality in university students: a cross-sectional study. Rev Bras Enferm. 2015;68(3):504-9. DOI: 10.1590/0034-7167.2015680318i

23- Marinho ACF, Medeiros AM, Gama ACC, Teixeira LC. Fear of public speaking: perception of college students and correlates. J Voice 2017;31(1):127-31.

DOI:
24- Figueiredo LZP, Barboza RV. Fobia social em estudantes universitários. Conscientiae Saúde 2008;7(1):109-15.

DOI:

10.5585/conssaude.v7i1.704

25- Souza DL, Zambalde AL. Desenvolvimento de competências e ambiente acadêmico: Um estudo em cursos de Administração de Minas Gerais, Brasil. Rev Adm. 2015;50(3):338-52. DOI: 10.5700/rausp1204

26- Kamath A, Urval RP, Shenoy AK. Effect of alternate nostril breathing exercise on experimentally induced anxiety in healthy volunteers using the simulated public speaking model: A randomized controlled pilot study. Biomed Res Int. 2017;2017:2450670. DOI: https://doi.org/10.1155/2017/2450670

27- Oliveira MA, Duarte ÂMM. Controle de respostas de ansiedade em universitários em situações de exposições orais. Rev Bras Ter Comport Cogn. 2004;6(2):183-99. DOI: $10.31505 /$ rbtcc.v6i2.56

28- Bhana VM. Interpersonal skills development in generation y student nurses: A literature review. Nurse Educ Today 2014;34(12):1430-34. DOI: 10.1016/i.nedt.2014.05.002

29- Westenberg PM, Bokhorst CL, Miers AC, Sumter SR, Kallen VL, Van Pelt J, et al. A prepared speech in front of a pre-recorded audience: Subjective, physiological, and neuroendocrine responses to the Leiden Public Speaking Task. Biol Psychol. 2009;82(2):116-24. DOI: 10.1016/j.biopsycho.2009.06.005

30- Stupar-Rutenfrans S, Ketelaars LEH, Van Gisbergen MS. Beat the fear of public speaking: Mobile $360^{\circ}$ video virtual reality exposure training in home environment reduces public speaking anxiety. Cyberpsychol Behav Soc Netw. 2017;20(10):624-33.

DOI: 10.1089/cyber.2017.0174

31- Zuardi AW, Crippa JA, Hallak JE, Gorayeb R. Human experimental anxiety: Actual public speaking induces more intense physiological responses than simulated public speaking. Braz J Psychiatry 2013;35(3):248-53. DOI: 10.1590/1516-4446-2012-0930

32- Tejwani V, Ha D, Isada C. Public speaking anxiety in graduate medical education: A matter of interpersonal and communication skills? J Grad Med Educ. 2016;8(1):111. DOI: 10.4300/JGME-D$\underline{15-00500.1}$

33- Tarkowski R. Reflections: Improving medical students' presentation skills. J Cancer Educ. 
2017;32:935-37. DOI: $10.1007 / \mathrm{s} 13187-016-1005-$

$\underline{6}$

Note: A pesquisa não contou com financiamento. Artigo extraído de dissertação entitulada: Competência em Oratória e Comunicação Interpessoal de estudantes de enfermagem em ambiente universitário.

Received in: $16 / 07 / 2019$

Approved in: 13/12/2019

Mailing address:

Alfredo Almeida Pina-Oliveira

Teresa Cristina Square, 229 - Downtown.

ZIP CODE: 07023-070 - Guarulhos/SP - Brazil

E-mail: alfredo.almeida@prof.ung.br 